\title{
Evolving Concept of Resilience: Soft Measures of Flood Risk Management in Japan
}

\section{Mikio Ishiwatari}

The University of Tokyo, https://www.k.u-tokyo.ac.jp/

\begin{abstract}
The concept of resilience is evolving to reflect various changes in climate, socio-economy, technology, etc. This article analyzes areas affecting resilience by reviewing the policy change of flood risk management, particularly soft measures, in Japan. Japan has coped with natural disasters throughout its history and succeeded in reducing flood damage. In particular, the government had invested in the infrastructure of flood protection at the level of $1 \%$ of the National Income for the last half-century and thus became able to protect major cities from flooding by major rivers. While major rivers are well protected, risk areas adjacent to small rivers and hill areas remain exposed to repeated flooding. Since the 2000s, the country is expanding soft measures, such as hazard mapping, early warning, and promoting evacuation to protect people's lives. The article examines the evolving processes of soft measures by reviewing the revision of floodfighting law. It was found that the concept of resilience in soft measures is evolving according to various changes, such as financial constrain, decreasing investment in infrastructure, aging population, urbanization, technology development, and climate. Based on lessons from the evolving concept of resilience, the author recommends that developing countries should implement soft measures considering various changes in socioeconomic and natural conditions and invest in infrastructure.
\end{abstract}

Keywords: flood protection, Japan, investment, infrastructure, flood fighting, risk mapping.

\section{Introduction}

The concept of resilience is evolving in reflection of various changes in climate, socio-economy, technology, and other factors. Each country attempts to strengthen its resilience to disasters according to its local condition. 
Japan has a rich historical experience in flood risk management. The country has increased its investment in flood protection infrastructure and succeeded in decreasing damage. The country has also revised the flood-fighting law to respond to emerging needs of soft measures, such as evacuation planning, information sharing, and hazard mapping.

This article aims to analyze areas that affect evolving resilience by reviewing the policy changes of flood risk management in Japan, particularly soft measures. Further, it provides other countries with policy recommendations in flood risk management based on its own findings and lessons learned.

\section{The Resilience Concept in Japan}

The United Nations Office for Disaster Risk Reduction ${ }^{1}$ defines resilience as "the ability of a system, community or society exposed to hazards to resist, absorb, accommodate, adapt to, transform and recover from the effects of a hazard in a timely and efficient manner, including through the preservation and restoration of its essential basic structures and functions through risk management." To strengthen resilience, coordinating institutions, risk identification and reduction, preparedness, financial and social protection, and resilient reconstruction are needed. ${ }^{2}$ Shiozaki and Kato ${ }^{3}$ argue that engineering resilience is crucial for quick recovery and that risks in urban systems can be managed by recognizing recoverable impacts.

The Japanese government is promoting initiatives for building national resilience to create safe and secure national lands, regions, and economic society that have strength and flexibility, even in the event of any disasters. ${ }^{4}$ The basic goals are (a) to prevent human loss, (b) to avoid fatal damage to important functions for maintaining administration as well as social and economic systems, (c) to mitigate damage to property of the citizenry and public facilities, and (d) to achieve swift recovery and reconstruction. The government planned to invest 7 trillion JPY, some 64 billion USD, in infrastructure development of disaster risk reduction from 2018 until 2020. The government uses 'resilience' as the concept of minimizing damage from crisis, realizing rapid recovery, and building sustainable and

1 United Nations Office for Disaster Risk Reduction (UNDRR), "Terminology," https://www.undrr.org/terminology.

2 World Bank, Building Resilience: Integrating Climate and Disaster Risk into Development (Washington, DC: World Bank, 2013), https://openknowledge.worldbank.org/ handle/10986/16639.

3 Yuto Shiozaki and Takaaki Kato, "Definitions of Resilience and Vulnerability in Natural Disaster Research and Related Fields," Seisan Kenkyu 64, no. 4 (2012): 643-646, https://doi.org/10.11188/seisankenkyu.64.643. - in Japanese.

4 Cabinet Secretariat, "Building National Resilience - Creating a Strong and Flexible Country" (Tokyo: Cabinet Secretariat), https://www.cas.go.jp/jp/seisaku/kokudo_ kyoujinka/index_en.html. 
equitable cities. However, experts and researchers use 'resilience' with different meanings, and there is no common theory of disaster resilience. ${ }^{5}$

Studies have examined how various sectors contribute to strengthening community resilience in Japan. Ishayama and Shaw ${ }^{6}$ argue that community networks created through daily healthcare activities by social welfare, medical, and local government organizations contribute to strengthening local communities' resilience. School Centered Community Building, promoted by the education ministry, restores community resilience following the Great East Japan Earthquake and Tsunami in 2011. Schools become multi-functional facilities, supporting disaster management by involving local communities in school management and educational activities. ${ }^{7}$ Societal activities in local communities, such as festivals, religious activities, and sports events, enhance relationships in communities, leading to strengthening communities' resilience. ${ }^{8}$ However, these literature sources do not cover the evolution of the concepts of resilience in flood risk management in Japan.

\section{Historical Overview of Disaster Risk Reduction in Japan}

Japan has fought against disasters through its long history and fostered a culture of disaster risk reduction. ${ }^{9}$ The Emperor ordered the construction of embankments along Yodogawa River to protect the Osaka plain in the 4th century. The national administrations of Bakufu and Emperor, as well as Daimyo, federal lords, constructed structures to protect the strategic areas of castles and major cities from flooding by using local knowledge and materials in the middle ages and early modern period. Also, local communities were engaged in flood fighting to protect themselves and their own assets. The modernized Meiji Government introduced Western technology of flood protection from The Netherlands and other western countries in the 19th century and started constructing large-scale structures to protect agricultural lands and cities from flooding.

5 Ryoga Ishihara, "Formation and Development of 'Disaster Resilience Theory' in Japan," in Depopulation, Deindustrialisation and Disasters, ed. Katsutaka Shiraishi and Nobutaka Matoba (Palgrave Macmillan, Cham, June 2019), 253-273, https://doi.org/10.10 07/978-3-030-14475-3_13.

6 Kenji Isayama and Rajib Shaw, "Building Disaster Resilient Community Through Healthcare Networking," in Community Practices for Disaster Risk Reduction in Japan, Disaster Risk Reduction: Methods, Approaches and Practices Series, ed. Rajib Shaw (Tokyo: Springer Japan, 2014), 91-120.

7 Shohei Matsuura and Rajib Shaw, "Concepts and Approaches of School Centered Disaster Resilient Communities," in Community Practices for Disaster Risk Reduction, 6389.

8 Miwa Abe and Rajib Shaw, "Community Resilience After Chuetsu Earthquake in 2004: Extinction or Relocation?" in Community Practices for Disaster Risk Reduction, 191208.

9 Satoru Nishikawa, "From Yokohama Strategy to Hyogo Framework: Sharing the Japanese Experience of Disaster Risk Management," Asian Journal of Environment and Disaster Management 2, no. 3 (2010): 249-262, https://doi.org/10.3850/S179392401 1000459. 
Japan succeeded in decreasing flood damage by investing in infrastructure for flood protection. A series of floods occurred in the 1940s and 1950s and caused considerable human losses and economic damage. The damage to the economy reached $10 \%$ of the National Income in 1947, and over 5,000 people died in 1959. This is because the government could not allocate enough funding for flood protection because of military expansion and the wars in the 1930s and 40s. ${ }^{10}$ The government invested in infrastructure for flood protection at the level of approximately $1 \%$ of the National Income from the 1940 s until the 1990 s. Tsukahara and Kachi ${ }^{11}$ estimate the annual benefit from these investments at over 6 trillion JPY, or 55 billion USD, in the mid-1990s, which is almost double the investment. The death toll decreased to less than 300 in the 1990s, and the economic damage decreased to less than $0.3 \%$ of the National Income (Figure 1 ).

Japan could prevent almost all flooding by major rivers because of investment in infrastructure for the half-century. However, the country cannot perfectly prevent flooding in urban areas by small and medium rivers, and the tributaries of major rivers, as well as landslides and debris flows in hill areas.

Since the 2000s, the government has decreased the budgets for flood protection due to national budget constraints, and various issues have emerged in every flood. The evacuation of people isolated in inundation areas has been delayed even though government organizations have issued warnings and evacuation orders. Local governments have been unable to issue timely evacuation orders to evacuate people in risk areas because of their limited capacity. The capacity for mutual efforts in local communities is reduced due to urbanization and the aging population. The vulnerable groups of the elderly and handicapped are facing difficulties in escaping from flooding. In 2018, over 200 people died in the western Japan region because of flooding caused by torrential rain at unprecedented scale. That was the highest number of causalities since 2004.

\section{Evolving Concept of Resilience and Soft Measures}

The history of revising the flood-fighting law illustrates the evolution of the concept of resilience against flooding in Japan. In addition to structural measures, the country has developed soft measures, starting with flood-fighting activities in the field, followed by issuing warnings covering small and medium rivers, hazards' mapping and sharing risk information, promoting evacuation, involving the private sector, and protecting vulnerable groups as shown in Table 1.

10 Mikio Ishiwatari and Kenichi Tsukahara, "Technical Note on the Estimation of Infrastructure Demand for Flood Control," in Bridging the Infrastructure Gap in Asia, ADBJICA Joint Side Event at the 50th Annual Meeting of the ADB Board of Governors" (Yokohama, 2017), https://www.jica.go.jp/jica-ri/publication/other/I75nbg00000w ej43-att/5_JICA_Technical_Notes_DRR.pdf.

11 Kenichi Tsukahara and Noriyasu Kachi, "Using Data and Statistics to Explain Investment Effectiveness on Flood Protection," Journal of Disaster Research 11, no. 6 (2016): 1238-1243, https://doi.org/10.20965/jdr.2016.p1238. 


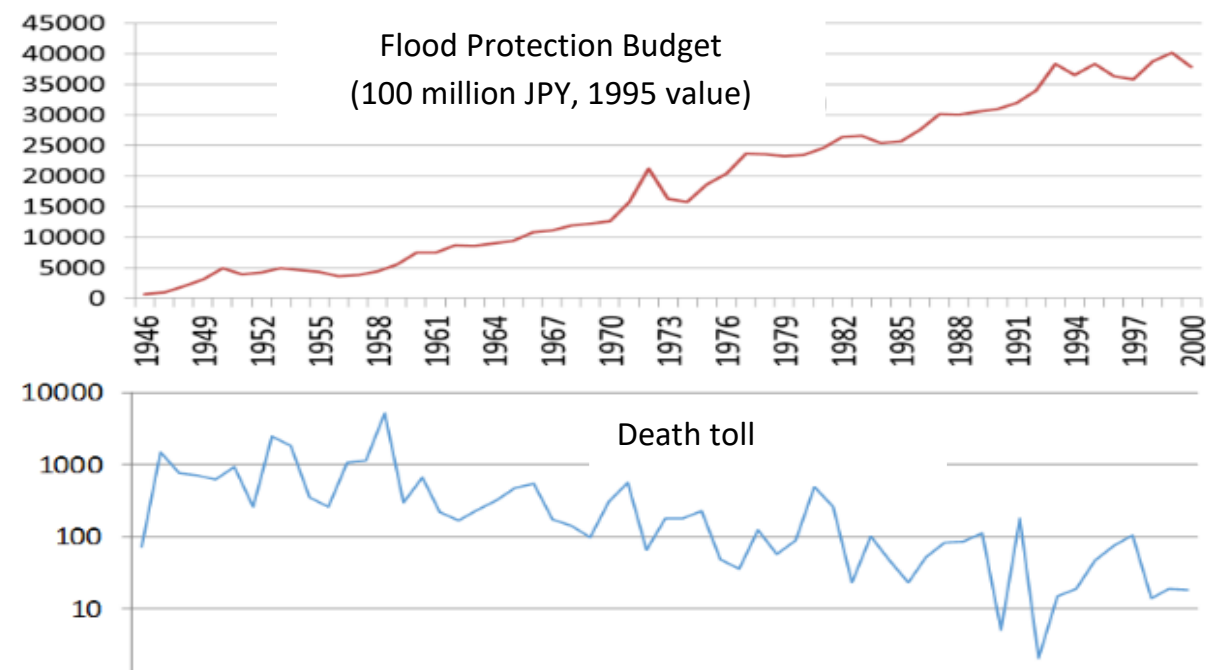

Figure 1: Budgets of Flood Protection and Death Toll in Japan.

Source: Mikio Ishiwatari, Japanese Disaster Management and Disasters in the World (Tokyo:

Kashima Syuppankai, 2016). - in Japanese.

Table 1: History of Revising Flood-Fighting Law.

\begin{tabular}{|l|l|l|}
\hline Year & \multicolumn{1}{|c|}{ Contents of revision of the law } & \multicolumn{1}{c|}{ Disasters } \\
\hline 1949 & $\begin{array}{l}\text { The law was enacted. } \\
\text { Flood-fighting in the field }\end{array}$ & a series of flooding \\
\hline 1955 & Flood forecasting and warning & Urban flood in Nagoya \\
\hline 2001 & $\begin{array}{l}\text { Risk mapping } \\
\text { Covering small-and medium-rivers }\end{array}$ & $\begin{array}{l}\text { torrential rains and ty- } \\
\text { phoons }\end{array}$ \\
\hline 2005 & $\begin{array}{l}\text { Protecting vulnerable groups } \\
\text { Protecting flood-fighting members } \\
\text { National government's support at the } \\
\text { large-scale disasters }\end{array}$ & $\begin{array}{l}\text { Great East Japan Earth- } \\
\text { quake \& Tsunami }\end{array}$ \\
\hline 2013 & $\begin{array}{l}\text { Involving the private sector } \\
\text { Responding to mega flooding }\end{array}$ & $\begin{array}{l}\text { torrential rains and ty- } \\
\text { phoons }\end{array}$ \\
\hline 2015 & $\begin{array}{l}\text { A mechanism for coordination among con- } \\
\text { Evacuation planning and conducting drills } \\
\text { for the vulnerable group }\end{array}$ & $\begin{array}{l}\text { Heavy rainfall in Kanto } \\
\text { and Tohoku }\end{array}$ \\
\hline
\end{tabular}


The flood-fighting law was enacted in 1949. Since a series of floods killing roughly 1,000 people happened almost every year in the late 1940s and 1950s, Japan needed to strengthen the systems of managing flood disasters. The law aims to protect local communities from floods and mitigate flood damage, leading to sustaining public safety. The law covers flood-fighting activities in the field by stipulating the primary responsibility of local governments and establishing flood-fighting organizations.

Japan has a centuries-old tradition of community-based activities of floodfighting to protect their own local communities. The members of flood-fighting organizations are engaged in patrolling riverbanks, issuing an early warning, supporting evacuation, and reinforcing riverbanks during flooding, as well as piling stocks of materials and conducting drills at normal times. Since flood-fighting is embedded in societal activities in the water management of local communities, its origin is unclear. Local communities started being engaged in flood protection, while new paddy fields were developed in the middle age..$^{12}$

In 1955, the law was revised to cover sharing flood information. The government organizations started issuing flood warnings to the public in major rivers managed by the national government and warning of flood-fighting to local governments. The warning of flood-fighting consists of three stages of (a) preparation, (b) mobilization, and (c) action. The river offices of the national government estimate the particular stage by floodwater levels.

The law had not been revised for nearly half a century but has been revised every several years starting in 2001. The reason is that the government is expected to respond to evolving issues, such as flooding in urban areas and small and medium-sized rivers and waning flood-fighting organizations. While the government has constructed structural measures, the country could not reduce the death toll further.

In 2000, the Nagoya Metropolitan area suffered from flooding. The evacuation was delayed and underground facilities and subways were submerged. It was found that government organizations did not provide the public with enough flood information and that the ordinary people did not recognize flood risks.

In 2001, the next year of the Nagoya flood, the flood-fighting law was revised for prefectural governments to issue flood warnings in small and medium-sized rivers. National and prefectural governments started sharing risk information of potential inundation areas and depth with municipality governments. The law requires municipal governments to prepare evacuation by issuing evacuation orders and designating evacuation shelters as well as sharing hazard and information maps with the public. The municipal governments need to provide flood information for evacuation in underground facilities as well.

12 Mikio Ishiwatari, "Government Roles in Community-Based Disaster Risk Reduction," in Community-Based Disaster Risk Reduction, ed. Rajib Shaw (Bingley: Emerald Group Publishing, 2012), 19-33, https://doi.org/10.1108/S2040-7262(2012)0000010008. 
In 2005, the country suffered several times from flooding caused by typhoons and torrential rains. Several issues were found. Some $60 \%$ of causalities are the elderly. Flood forecasts cover only major rivers and did not include information on inundation areas and depths.

In 2006, the law was revised to provide flood risks and flood warning in small and medium rivers and to include inundation prediction of areas and depths in the flood warning. Local governments became obligated to provide hazard and evacuation maps and formulate communication routes to facilities for the vulnerable groups of the elderly and children. Furthermore, the municipal governments design evacuation plans for underground facilities. Support organizations to flood fighting were established to strengthen the flood-fighting capacity.

In 2011, the Great East Japan Earthquake and Tsunami caused over 20,000 dead or missing people and USD 150 billion of economic losses. Over 200 members of flood-fighting organizations died during disaster management activities. The law was revised to cover tsunami disasters and to protect the lives of members of flood-fighting organizations. National governmental organizations can be engaged in flood fighting at mega-disasters.

The flood-fighting capacities of local communities weakened because of urbanization and changes in the industrial structure. The farming population declined, and young generations in rural areas migrated to metropolitan areas to find job opportunities. The number of flood fighters decreased, and they are aging. In 2013, the law was revised to involve the private sector in flood fighting to support local communities. Also, national governmental organizations support flood-fighting activities in the field. Private companies are required to formulate contingency plans to mitigate the damage of private facilities and supply-chain among private companies.

At scales larger than the designed safety levels of structural measures, flooding repeatedly occurred throughout the country in the 2010s. In 2015, the law was revised to respond to large-scale floods that structural measures cannot prevent. The governments formulate hazard maps that show the risks of maximum possible floods, high tides, and urban floods, the scale of which is set at once-inone-thousand-years intensity.

In 2015 and 2016, affected people did not escape from flooding and isolated in inundated areas. In the Iwate Prefecture, all nine elderlies could not escape and died by flooding at an elderly facility.

In 2016, the law was revised to provide for the protection of vulnerable groups. The property owners of hospitals, schools, and facilities for the elderly are obliged to formulate evacuation plans and conduct evacuation drills. Some 4,000 facilities need to take these actions throughout the country. To strengthen collaborative mechanisms, the national and prefectural governments establish coordinating committees representing the organizations concerned, such as meteorology offices, river management offices, local governments, police, fire departments, the self-defense force, and private companies. 


\section{Factors Causing Evolution}

This section examines the factors affecting the resilience of flood risk management. Japan could reduce economic damage and casualties by flooding from the 1940 s to the 1990s (Table 2). This is mainly because the government invested in structural measures to protect flooding by major rivers. Soft measures mainly covered flood-fighting on site and information sharing related to major rivers.

Table 2: Developing Soft Measures, Investment, and Flood Damage.

\begin{tabular}{|c|c|c|c|c|c|c|c|c|}
\hline & $1940 s$ & $50 \mathrm{~s}$ & $60 \mathrm{~s}$ & $70 s$ & $80 \mathrm{~s}$ & $90 \mathrm{~s}$ & $2000 s$ & $10 \mathrm{~s}$ \\
\hline flood-fighting & & & & & & & & \\
\hline $\begin{array}{l}\text { Forecasting and } \\
\text { warning }\end{array}$ & & & & & & & & \\
\hline Hazard mapping & & & & & & & & \\
\hline Evacuation & & & & & & & & \\
\hline $\begin{array}{l}\text { Budget of flood pro- } \\
\text { tection, \% National } \\
\text { Income }\end{array}$ & $\begin{array}{l}0.5- \\
2.0\end{array}$ & \multicolumn{5}{|c|}{$0.8-1.5$} & & \\
\hline Death toll & \multicolumn{2}{|c|}{$<6,000$} & \multicolumn{3}{|c|}{$<1,000$} & \multicolumn{3}{|c|}{$<300$} \\
\hline $\begin{array}{l}\text { Economic damage, \% } \\
\text { of National Income }\end{array}$ & \multicolumn{2}{|c|}{$0.9-10.2$} & $<2.0$ & $<0.8$ & $<0.6$ & $<0.3$ & & \\
\hline
\end{tabular}

The death toll decreased to less than 300 in the 1990s but did not decrease further. Perfectly preventing flooding caused by small and medium-sized rivers and flash floods in hill areas is difficult. For example, there are still 300,000 areas at risk of landslides.

Flood-fighting capacities of local communities had declined because of urbanization and changes in the industrial structure. The government needs to strengthen soft measures. The national and local governments started formulating hazard maps and distributing the maps to the public. The development of technology to simulate flooding contributed to devising hazard maps. The governments have strengthened the evacuation measures, particularly for protecting vulnerable groups of the elderly and handicapped and the vulnerable areas of underground facilities.

\section{Conclusion}

The Japanese experience demonstrates that investment in infrastructure is effective in decreasing flood damage, but such structural measures can mainly cover major rivers. Protecting all risk areas related to small rivers and landslides is unrealistic, considering the country's enormous number of risk areas. Japan started strengthening soft measures to decrease causality further in the 2000s. 
It was found that the concept of resilience through soft measures is evolving in line with various changes, such as financial constraints, investment in infrastructure, aging population, urbanization, technology development, and climate change. The coverage of soft measures expands from flood-fighting on-site to information sharing, hazard mapping, promoting evacuation, and protecting the vulnerable groups. While local communities have played a leading role in soft measures for the last centuries, government organizations and the private sector became more recently engaged in flood fighting and risk mitigation measures. This is because the relationships between members of local communities have weakened, and the private sector's role has increased in local communities.

\section{Consideration}

Lessons can be learned from the Japanese experience. These lessons are useful for developing countries increasingly exposed to flood disasters. Developing countries should invest in the infrastructure of flood protection as a cost-effective measure. Besides, developing countries should develop soft measures considering various changes in socioeconomic and natural conditions. As their economies grow, developing countries experience urbanization, changes in industrial structure, and migration from rural to urban areas just as Japan has experienced.

\section{Disclaimer}

The views expressed are solely those of the author and do not represent official views of the PfP Consortium of Defense Academies and Security Studies Institutes, participating organizations, or the Consortium's editors.

\section{Acknowledgment}

Connections: The Quarterly Journal, Vol. 19, 2020 is supported by the United States government.

\section{About the Author}

Dr. Mikio Ishiwatari is a Visiting Professor, The University of Tokyo, and a Senior Advisor in disaster management and water resources management for the Japan International Cooperation Agency (JICA). He provides advice and guidance on JICA's policies and operations and conducts research and project formulation, administration, and review in the areas of climate change adaptation, disaster management, and water resources management. Dr. Ishiwatari has also served as a government engineer at the Ministry of Land, Infrastructure, Transport and Tourism, Japan, an urban development specialist at the Asian Development Bank, and a senior disaster risk management specialist in the World Bank.

E-mail: Ishiwatari.mikio@jica.go.jp 